\title{
Malignant hyperthermia when dantrolene is not readily available
}

Xiaodan Gong ${ }^{1,2}$

\begin{abstract}
Background: Malignant hyperthermia is a rare but life-threatening pharmacogenetic muscle disorder characterized by abnormal hypermetabolic reactions and commonly triggered in susceptible individuals by volatile anesthetics or succinylcholine, or both. Unfortunately, the specific medicine dantrolene is not readily available in many countries including China. The aim of this study was to find the characteristics of malignant hyperthermia under the situation that dantrolene is not readily available.

Methods: The cases of malignant hyperthermia reported on the most commonly used databases in China from 1985 to 2020 were analyzed. The inclusion criteria were the MH episodes only related to anesthesia. The exclusion criteria were dubious MH episodes only caused by Ketamine administration or MH episodes irrelevant to anesthesia. Independent samples t-test and Pearson's chi-squared test were applied to assess the difference between the survived and death cases.

Results: Ninety-two cases of malignant hyperthermia reported on the most commonly used databases in China from 1985 to 2020 were analyzed. Median (IQR [range]) age was 18.5 (11.8-37.0 [0-70.0]) years. Compared with the survived cases, the death cases had higher maximum end-tidal partial pressure of $\mathrm{CO}_{2}(P=0.033)$, the maximum arterial partial pressure of $\mathrm{CO} 2(P=0.006)$, temperature first measured when the patient was first discovered abnormal $(P=0.012)$, and maximum temperature $(P<0.001)$. Besides, the death cases had less minimum $\mathrm{pH}(P<$ $0.001)$ and higher potassium $(P<0.001)$ and were more likely to have coagulation disorders $(p=0.018)$. Concerning treatment, cases used furosemide $(P=0.024)$, mannitol $(P=0.029)$, blood purification treatment $(P=0.017)$ had the advantage on the outcome. Creatine phosphokinase, myoglobin, and MB isoenzyme of creatine phosphokinase differed greatly among cases during the first week. 43 (46.7\%) cases had congenital diseases. 12 (13.0\%) cases were reported with abnormal laboratory test results or abnormal signs that are possibly relevant before anesthesia.
\end{abstract}

Conclusions: In countries that dantrolene is not readily available, early warning, diagnosis, and prompt effective therapies are crucial for $\mathrm{MH}$ patients to survive.

Keywords: Malignant hyperthermia, Dantrolene, Mortality, Enzyme, Treatment

\footnotetext{
Correspondence: xiaodan.gong@charite.de

${ }^{1}$ Department of Cardiology, Charité - Universitätsmedizin Berlin, corporate member of Freie Universität Berlin and Humboldt-Universität zu Berlin,

Charité University Medicine, Campus Virchow Klinikum, Augustenburger Platz

1, 13353 Berlin, Germany

${ }^{2}$ Department of Anesthesiology, The Second Clinical Medical College,

Yangtze University, Jingzhou 434020, China
}

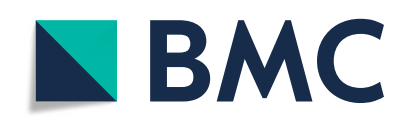

(c) The Author(s). 2021 Open Access This article is licensed under a Creative Commons Attribution 4.0 International License, which permits use, sharing, adaptation, distribution and reproduction in any medium or format, as long as you give appropriate credit to the original author(s) and the source, provide a link to the Creative Commons licence, and indicate if changes were made. The images or other third party material in this article are included in the article's Creative Commons licence, unless indicated otherwise in a credit line to the material. If material is not included in the article's Creative Commons licence and your intended use is not permitted by statutory regulation or exceeds the permitted use, you will need to obtain permission directly from the copyright holder. To view a copy of this licence, visit http://creativecommons.org/licenses/by/4.0/ The Creative Commons Public Domain Dedication waiver (http://creativecommons.org/publicdomain/zero/1.0/) applies to the data made available in this article, unless otherwise stated in a credit line to the data. 


\section{Background}

Malignant hyperthermia $(\mathrm{MH})$ is a rare but lifethreatening pharmacogenetic muscle disorder characterized by abnormal hypermetabolic reactions and commonly triggered in susceptible individuals by volatile anesthetics or succinylcholine, or both. The incidence of $\mathrm{MH}$ is estimated between $1 / 5000$ and $1 /$ 250000 anesthetics [1-5]. However, the real prevalence of $\mathrm{MH}$ susceptibility is very much higher because most people with $\mathrm{MH}$-related genetic mutations never undergo any anesthesias during their lives. Indeed, the predicted genetic prevalence is reported between $1 / 2000$ and $1 / 3000$, and another study reported the prevalence may be as high as $1 / 400$ [6-8]. Malignant hyperthermia mortality reached up to $70 \%$ before the introduction of dantrolene [9]. Another study showed the mortality rate was $64 \%$ before administration approval of dantrolene [10]. Unfortunately, the specific medicine dantrolene is not readily available in many countries. Due to low incidence, high cost, and short life span, it is quite difficult to get dantrolene when $\mathrm{MH}$ episodes happen in the great majority of hospitals in China as well. In China, $\mathrm{MH}$ has been often mostly reported in the form of case reports. In the vast majority of cases, dantrolene was not administered. The aim of this study was to find the characteristics of $\mathrm{MH}$ under the situation that dantrolene is not readily available.

\section{Methods}

The keyword 'malignant hyperthermia' was used to search in Wanfang Database, China National Knowledge Infrastructure, China Science and Technology Journal Database, and China Biology Medicine Database, which are the most commonly used databases in China. Exclusion criteria were dubious $\mathrm{MH}$ episodes only caused by Ketamine administration or $\mathrm{MH}$ episodes irrelevant to anesthesia.

The $\mathrm{MH}$ clinical grading scale (CGS) was used to qualitatively assess the probability of the MH cases. CGS score range, $\mathrm{MH}$ rank, and qualitative probability are shown in Table 1. Based on the scoring rule, if more than one indicator represent a single process, only count

Table 1 Clinical grading scale

\begin{tabular}{lll}
\hline CGS points & MH rank & MH probability \\
\hline 0 & 1 & MH probability is almost never \\
$3-9$ & 2 & MH probability is unlikely \\
$10-19$ & 3 & MH probability is somewhat less than likely \\
$20-34$ & 4 & MH probability is somewhat greater than likely \\
$35-49$ & 5 & MH probability is very likely \\
$50-108$ & 6 & MH probability is almost certain \\
\hline
\end{tabular}

the indicator with the highest score [11]. For example, both increased creatine kinase (CK) to more than 10, 000 IU after anesthetic administration without succinylcholine (15 points) and cola-colored urine after anesthetic administration (10 points) represent the same process: muscle breakdown. Therefore, an individual with the above two abnormal signs and laboratory results would have only 15 points, not 25 points. But if authors offered the ranks or CGS scores, they were directly adopted.

Statistical analysis was performed using SPSS v24 (IBM Corp, Armonk, NY, USA). For continuous variables, for instance, age, maximum end-tidal and arterial $\mathrm{CO} 2$, temperature when the patient was first discovered abnormal, etc. in which survival and death groups of variables were compared. Descriptive statistics were expressed as mean (SD) and median (IQR [range]), and independent $\mathrm{t}$-test were used. For categorical variables, for instance, gender, generalized muscular rigidity, colacolored urine, etc., Pearson's chi-squared test was used to test the difference between the variables of the two groups by number (proportion). The $P$-value $<0.05$ was considered statistically significant.

\section{Results}

Totally 139 relevant articles were retrieved. Dubious $\mathrm{MH}$ episodes only caused by Ketamine administration and $\mathrm{MH}$ episodes irrelevant to anesthesia were ruled out. The process of identifying the eligible articles is outlined in Supplemental Figure 1. Eventually, 110 articles and 92 cases $(85.2 \%$ of $\mathrm{MH}$ episodes relevant to anesthesia administration reported) were included in the final analysis, but not all data were recorded and reported for these 92 cases [12-121]. Therefore, some variables included less than 92 cases and some patients' CGS points were underestimated or not estimated. 63 (68.5\%) cases were $\mathrm{MH}$ rank 6 representing the $\mathrm{MH}$ probability is almost certain. $15(16.3 \%)$ cases were $\mathrm{MH}$ rank 5 representing the $\mathrm{MH}$ probability is very likely. 4 (4.3\%) cases were $\mathrm{MH}$ rank 4 representing the $\mathrm{MH}$ probability somewhat greater than likely.

\section{Cases sources characteristics and demographics}

One hundred and ten articles and 92 cases in this study involved 13 departments (Fig. 1) and different years (Fig. 2). The median age was $18.5(11.8-37.0[0-70.0])$ years. $72(78.3 \%)$ cases were male and $20(21.7 \%)$ cases were female (Fig. 3).

\section{Outcomes}

A total of $50(54.3 \%)$ cases survived and $42(45.7 \%)$ cases died. From 1985 to 2010 the total mortality was 33 (54.1\%) cases, whereas the total mortality was down to 9 (29.0\%) cases from 2011 to 2020 (Table 2). Compared 


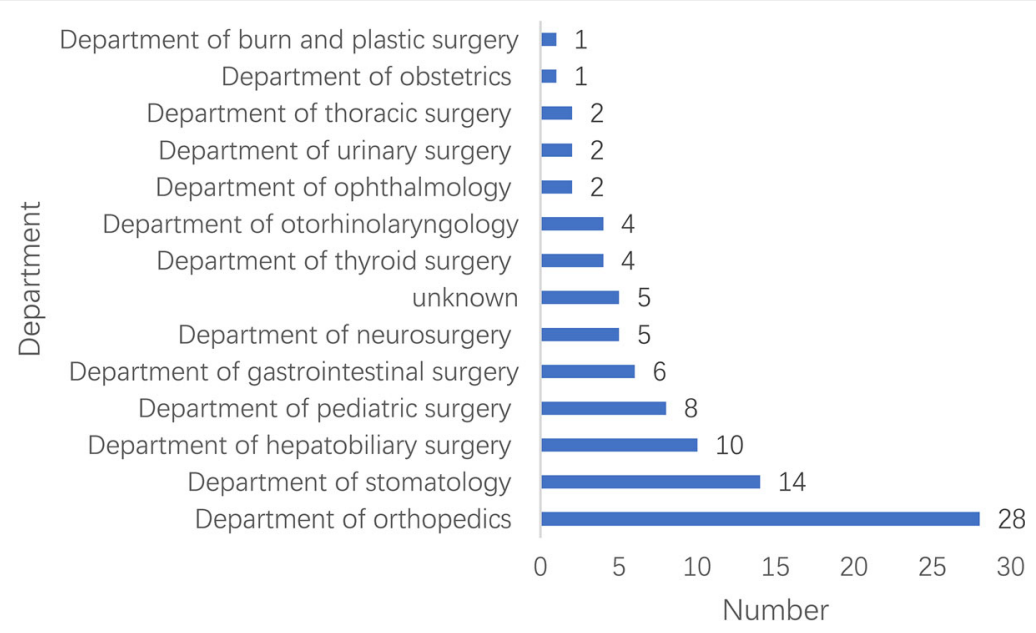

Fig. 1 Department distribution of $\mathrm{MH}$ cases

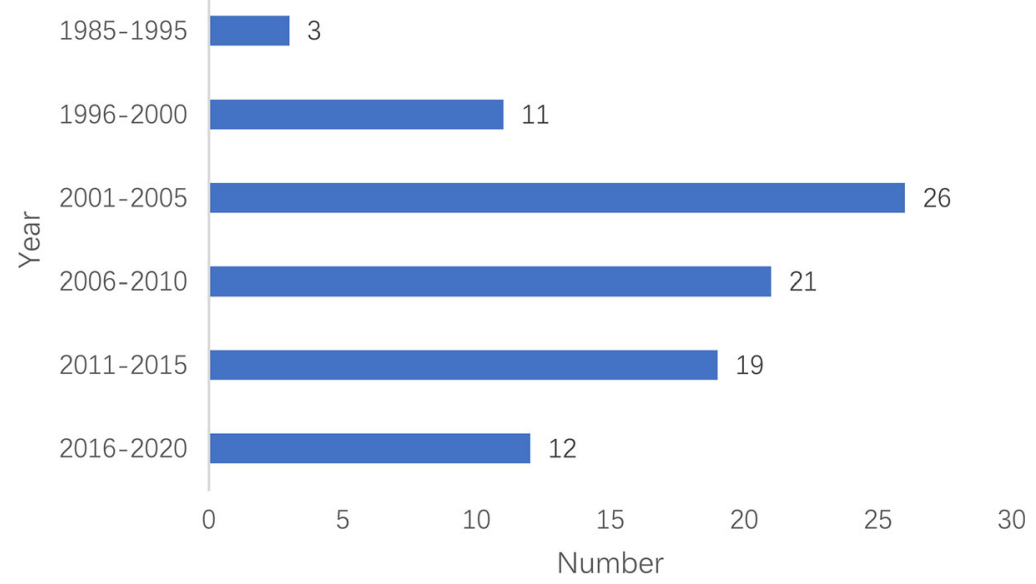

Fig. 2 Occurrence year distribution of MH cases

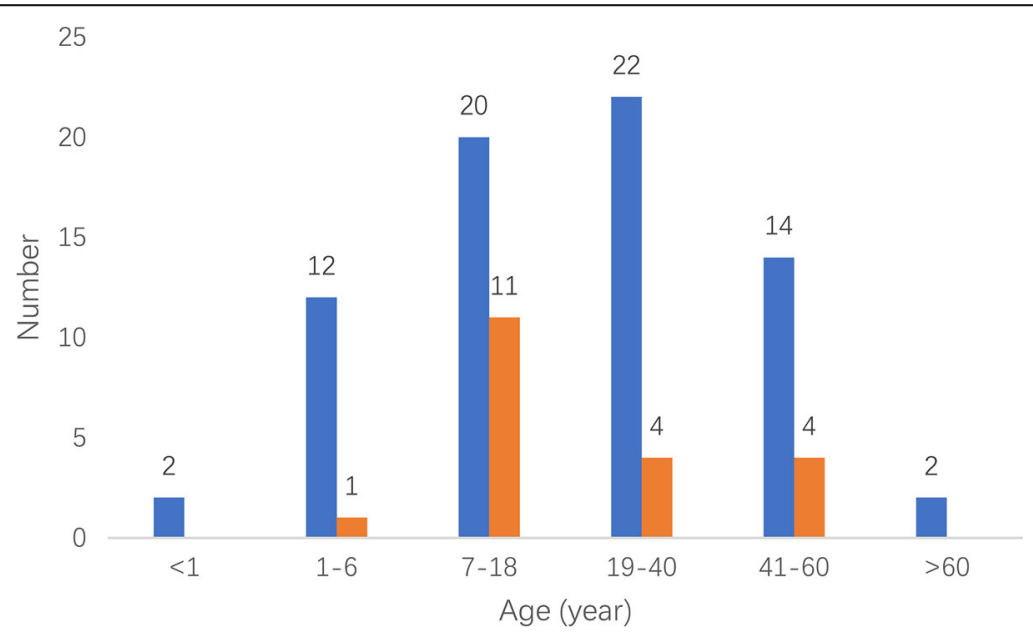

Fig. 3 Age distribution of $\mathrm{MH}$ cases. Blue, male; red, female 
Table 2 Outcome of MH cases. Values are number (proportion)

\begin{tabular}{lll}
\hline & Survived & Death \\
\hline total outcome between 1985 and $2010(n=61)$ & $28(45.9 \%)$ & $33(54.1 \%)$ \\
total outcome between 2011 and $2019(n=31)$ & $22(71.0 \%)$ & $9(29.0 \%)$ \\
outcome between 1985 and 2010 without dantrolene $(n=59)$ & $26(44.1 \%)$ & $33(55.9 \%)$ \\
outcome between 2011 and 2019 without dantrolene $(n=25)$ & $16(64.0 \%)$ & $9(36.0 \%)$ \\
\hline
\end{tabular}

with the previous phase, the total mortality in the latter phase decreased nearly by half $(P=0.023)$. Of total cases, $8(8.7 \%)$ cases were used dantrolene. Of the 50 survival cases excluding the 8 cases that used dantrolene, there were 29 cases with time data beginning to improve after treatment and the median (IQR [range]) time was 1.0 $(0.8-2.0[0.3-5])$ hours.

\section{Anesthetics}

Table 3 shows the frequency with which volatile anesthetics or succinylcholine, or both, were administered. Of 76 cases with anesthetics data, five cases used succinylcholine without volatile anesthetic, 17 cases used succinylcholine and volatile anesthetic, and 71 cases only used volatile anesthetic including $32(45.1 \%)$ cases isoflurane, 19 (26.8\%) cases used sevoflurane, 18 (25.4\%) cases used enflurane, and 2 (2.8\%) cases used halothane.

\section{The first clinical sign}

Of 83 cases with time data from induction of anesthesia to first abnormal sign interval, the median (IQR [range]) time was $1.3(0.5-2.0[0-18])$ hours. The most frequent initial signs were hypercarbia (31 (33.7\%)), sinus tachycardia (23 (25.0\%)), hyperthermia (18 (19.6\%)), and masseter spasm (10 (10.9\%)) (Table 4).

\section{Comparisons of survived and death cases}

Analysis of the age, gender, history of congenital disease, clinical sign, laboratory result, treatment, and CGS scores between the survived and death cases were as follows (Table 5). Compared with the survived cases, the death cases had higher maximum end-tidal partial pressure of carbon dioxide $\left(\mathrm{PCO}_{2}\right)(P=0.033)$, maximum arterial PCO2 $(P=0.006)$, temperature first measured when the patient was first discovered abnormal $(P=$ $0.012)$, and maximum temperature $(P<0.001)$. Besides,

Table 3 Anesthetics of MH cases. Values are number (proportion)

\begin{tabular}{ll}
\hline Anesthetic drug & Frequency $(\boldsymbol{n}=\mathbf{9 2})$ \\
\hline Succinylcholine + , Volatile - & $5(5.4 \%)$ \\
Succinylcholine + , Volatile + & $17(18.5 \%)$ \\
Succinylcholine -, Volatile + & $54(58.7 \%)$ \\
unrecorded & $16(17.4 \%)$ \\
\hline
\end{tabular}

the death cases had less minimum $\mathrm{pH}(\mathrm{P}<0.001)$ and higher potassium $(\mathrm{P}<0.001)$ and were more likely to have coagulation disorders $(p=0.018)$. Concerning treatment, cases used furosemide $(P=0.024)$, mannitol $(P=$ $0.029)$, blood purification treatment $(P=0.017)$ had the advantage on the outcome.

Table 5 Comparisons of survived and death cases. Values are mean (SD), median (IQR [range]) or number (proportion).

Table 4 The first clinical sign of MH cases. Values are number (proportion)

\begin{tabular}{ll}
\hline & Frequency $(\boldsymbol{n}=\mathbf{9 2})$ \\
\hline Elevation of end tidal $\mathrm{CO}_{2}$ & $31(33.7 \%)$ \\
Sinus tachycardia & $23(25.0 \%)$ \\
Rapidly increasing temperature & $18(19.6 \%)$ \\
Masseter spasm & $10(10.9 \%)$ \\
Unrecorded & $6(6.5 \%)$ \\
Reduction of oxygen saturation & $4(4.3 \%)$ \\
Reduction of blood pressure & $4(4.3 \%)$ \\
Convulsion & $3(3.3 \%)$ \\
Elevation of blood pressure & $3(3.3 \%)$ \\
Restlessness & $3(3.3 \%)$ \\
Muscular rigidity & $3(3.3 \%)$ \\
Poor muscle relaxation effectiveness & $3(3.3 \%)$ \\
Dark red blood at surgical field & $2(2.2 \%)$ \\
Elevation of muscular tension & $2(2.2 \%)$ \\
Sweating & $2(2.2 \%)$ \\
Elevation of airway resistance & $2(2.2 \%)$ \\
Neck stiffness & $2(2.2 \%)$ \\
Flushed face & $1(1.1 \%)$ \\
Cyanosis of nail beds & $1(1.1 \%)$ \\
Opisthotonos & $1(1.1 \%)$ \\
Hot soda lime canister & $1(1.1 \%)$ \\
Reduction of heart rate & $1(1.1 \%)$ \\
Depression of ST segment in ECG & $1(1.1 \%)$ \\
Excessive bleeding at surgical field & $1(1.1 \%)$ \\
Muscle tremors & $1(1.1 \%)$ \\
\hline CO & $1(1.1 \%)$ \\
\hline
\end{tabular}

$\mathrm{CO}_{2}$ carbon dioxide; $E C G$ electrocardiograph 
Table 5 Comparisons of survived and death cases. Values are mean (SD), median (IQR [range]) or number (proportion)

\begin{tabular}{|c|c|c|c|}
\hline & Survived & Death & $P$ value \\
\hline Age; y $(n=92)$ & $24.2(16.7)$ & $23.1(17.3)$ & 0.756 \\
\hline Sex; male $(n=92)$ & $40(80.0 \%)$ & $32(76.2 \%)$ & 0.659 \\
\hline Combined congenital disease $(n=92)$ & $21(42.0 \%)$ & $22(52.4 \%)$ & 0.32 \\
\hline First sign interval; $\mathrm{h}(n=83)$ & $1.0(0.2-2.8[0-11.0])$ & $1.5(1.0-2.0[0-18.0])$ & 0.787 \\
\hline Maximum end-tidal $\mathrm{PCO}_{2} ; \mathrm{mmHg}(n=39)$ & $85.0(71.8-101.3$ [60.0-149.0]) & $91.0(86.0-126.5[75.0-223,0])$ & 0.033 \\
\hline Maximum arterial $\mathrm{PCO}_{2} ; \mathrm{mmHg}(n=44)$ & 83.0 (73.9-99.4 [53.0-120.0]) & $101.0(87.8-152.2[52.8-250.0])$ & 0.006 \\
\hline $\mathrm{T}$ first measured; ${ }^{\circ} \mathrm{C}(n=64)$ & $38.5(38.0-39.1[35.8-43.0])$ & $39.3(38.6-41.1[37.0-42.5])$ & 0.012 \\
\hline Maximum $\mathrm{T} ;{ }^{\circ} \mathrm{C}(n=88)$ & $40.3(39.3-41.4[38.3-44.5])$ & $42.3(42.0-43.1[39.4-46])$ & $<0.001$ \\
\hline Maximum HR; bpm $(n=65)$ & $160.0(140.0-180.0[110.0-220.0])$ & $160.0(150.0-190.0[120-230.0])$ & 0.187 \\
\hline Generalised muscular rigidity $(n=92)$ & $29(58.0 \%)$ & $31(73.8 \%)$ & 0.113 \\
\hline Normal BP when first discovered $(n=92)$ & $18(36.0 \%)$ & $8(19.0 \%)$ & 0.072 \\
\hline Increased BP when first discovered $(n=92)$ & $1(2.0 \%)$ & $5(11.9 \%)$ & 0.055 \\
\hline No drop in BP when first discovered $(n=92)$ & 19 (38.0\%) & $13(31.0 \%)$ & 0.48 \\
\hline Cola-colored urine $(n=92)$ & $11(22.0 \%)$ & $12(28.6 \%)$ & 0.468 \\
\hline Oliguria or anuria $(n=92)$ & $9(18.0 \%)$ & $13(31.0 \%)$ & 0.147 \\
\hline Minimum $\mathrm{pH}(n=48)$ & $7.14(7.08-7.22[6.81-7.40])$ & $6.92(6.79-7.05[6.57-7.24])$ & $<0.001$ \\
\hline Potassium; mmol/L $(n=44)$ & $5.2(4.6-5.7[3.8-6.7])$ & $7.1(6.5-8.3[5.7-10.1])$ & $<0.001$ \\
\hline Coagulation disorders $(n=92)$ & $11(22.0 \%)$ & $19(45.2 \%)$ & 0.018 \\
\hline Patient used sodium bicarbonate $(n=92)$ & $31(62.0 \%)$ & $30(71.4 \%)$ & 0.341 \\
\hline Patient used glucocorticoid $(n=92)$ & $35(70.0 \%)$ & $31(73.8 \%)$ & 0.686 \\
\hline Patient used active cooling $(n=92)$ & $42(84.0 \%)$ & $30(71.4 \%)$ & 0.145 \\
\hline Patient used furosemide ( $n=92)$ & $32(64.0 \%)$ & $17(40.5 \%)$ & 0.024 \\
\hline Patient used mannitol $(n=92)$ & $12(24.0 \%)$ & $3(7.1 \%)$ & 0.029 \\
\hline Patient used blood purification treatment $(n=92)$ & $13(26.0 \%)$ & $3(7.1 \%)$ & 0.017 \\
\hline Clinical grading scale score; point $(n=82)$ & $58.0(51.0-63.0[33.0-73.0])$ & $58.0(51.0-61.0[33.0-73.0])$ & 0.809 \\
\hline
\end{tabular}

$\mathrm{PCO}_{2}$ partial pressure of carbon dioxide; $T$ temperature; $H R$ heart rate; $B P$ blood pressure

\section{Drug treatment}

Of 54 cases with vasoactive drugs data, the most commonly used medications were dopamine (57.4\%), epinephrine (53.7\%), and norepinephrine (25.9\%) (Supplemental Table 1). Besides the vasoactive agents mentioned in Supplemental Table 1 and agents mentioned in Table 5, 11 cases (12.9\%) were administered insulin, and 18 cases (19.6\%) were administered antibiotics.

\section{Enzymes}

Of total cases, 13 cases were recorded more enzyme data $[14,24,27,31,34,40,53,87,88,91,95,109,116]$. The CGS score of the patient six, eight and ten were graded by original authors. As Figs. 4, 5 and 6 shown, creatine phosphokinase (CPK), myoglobin, and creatine phosphokinase myocardial band (CPK-MB) varied greatly during the first week, and there were significant differences among these patients as well.
History of congenital disease and abnormal characteristics before anesthesia

$43(46.7 \%)$ cases had congenital diseases. 12 (13.0\%) cases were reported with abnormal laboratory test results or abnormal signs that are possibly relevant before anesthesia. Among these cases, 6 (6.5\%) cases were with increased CPK, 4 (4.3\%) cases with increased alkaline phosphatase (ALP), 2 (2.2\%) cases with increased CPK-MB,1 (1.1\%) cases with increased lactic dehydrogenase (LDH), and $3(3.3 \%)$ cases were recorded with a mildly elevated body temperature of unknown origin.

\section{Diagnostic testing}

Of the total cases, 7 (7.6\%) cases took relevant examinations and showed positive results. In three cases, the muscles of the patients were soaked in succinylcholine solutions and all of them tested positive and contracted strongly. Muscle biopsy was performed in four cases, among which one case showed hyaline degeneration in quadriceps femoris, one case with 


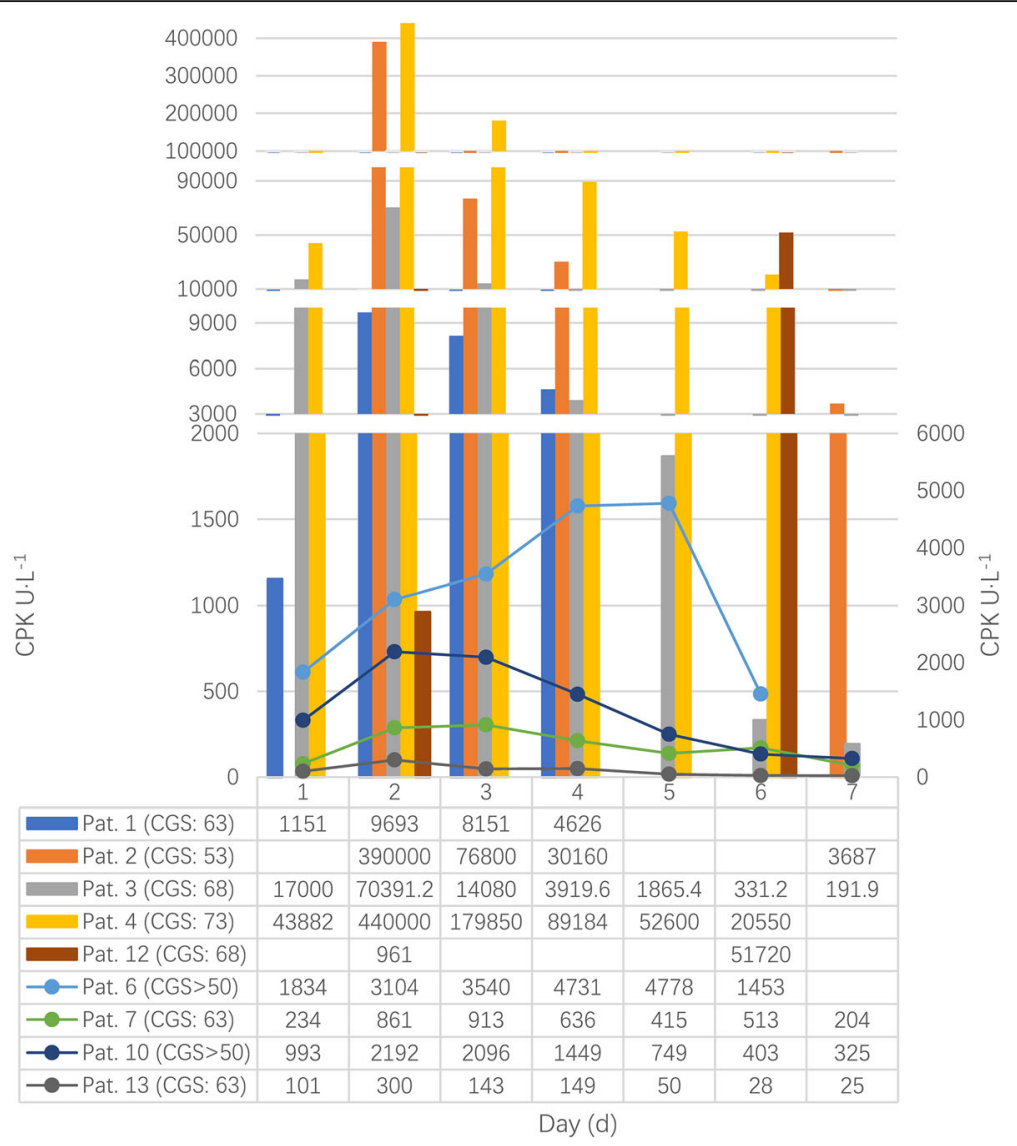

Fig. 4 Changes of creatine phosphokinase. CPK, creatine phosphokinase

vacuolar degeneration and myolysis in quadriceps femoris, one case with severe vacuolar degeneration in striated muscle, and one case with inflammatory and degeneration in gastrocnemius muscle. In another case, as Fig. 7 shown, seven members of the immediate family of the patient took the genetic testing and six members in red were tested positive and have MH susceptibility [45].

\section{Discussion}

Totally 110 articles and 92 cases were used from the most commonly used databases in China. Exclusion criteria were dubious $\mathrm{MH}$ episodes only caused by Ketamine administration or $\mathrm{MH}$ episodes irrelevant to anesthesia. This study may be limited by incomplete patient data and underreporting, but analysis bias seems to be minimal because there were no significant differences between comparisons of survived and death cases.

For the incident departments, they were concentrated in departments of orthopedics, stomatology, and hepatobiliary surgery. Around half of the incident years focused on 2001-2010. The male to female of MH cases was 3.5: 1. More than half of $\mathrm{MH}$ cases focused on the 7-18 and 19-40 demographic. In all these $\mathrm{MH}$ cases reported, the total mortality was $42(45.7 \%)$, less than the mortality rate 64-70\% reported before administration of dantrolene [9, 10]. Even in the absence of dantrolene, the mortality was down to $36.0 \%$ from 2011 to 2020 . In terms of anesthetics, more than half of all these cases were administered volatile anesthetic without succinylcholine, mainly including isoflurane, sevoflurane, and enflurane. Besides, the most frequent initial signs of these cases were hypercarbia, sinus tachycardia, hyperthermia, and masseter spasm.

Although there were no significant differences between comparisons of survived and death cases, some clues were still found from the analysis. From the comparisons, the death cases had higher maximum end-tidal $\mathrm{PCO}_{2}$, maximum arterial $\mathrm{PCO}_{2}$, temperature first measured when the patient was first discovered abnormal, maximum temperature and potassium, and had more serious metabolic acidosis and more possibility of coagulation disorders. On the treatment side, cases that used furosemide, mannitol, blood purification treatment had a significant advantage on the outcome, which showed renoprotective therapies play important roles in outcomes in these $\mathrm{MH}$ cases.

The 13 cases with more enzyme data were all at $\mathrm{MH}$ rank 6 . But there were wide differences in concentration 


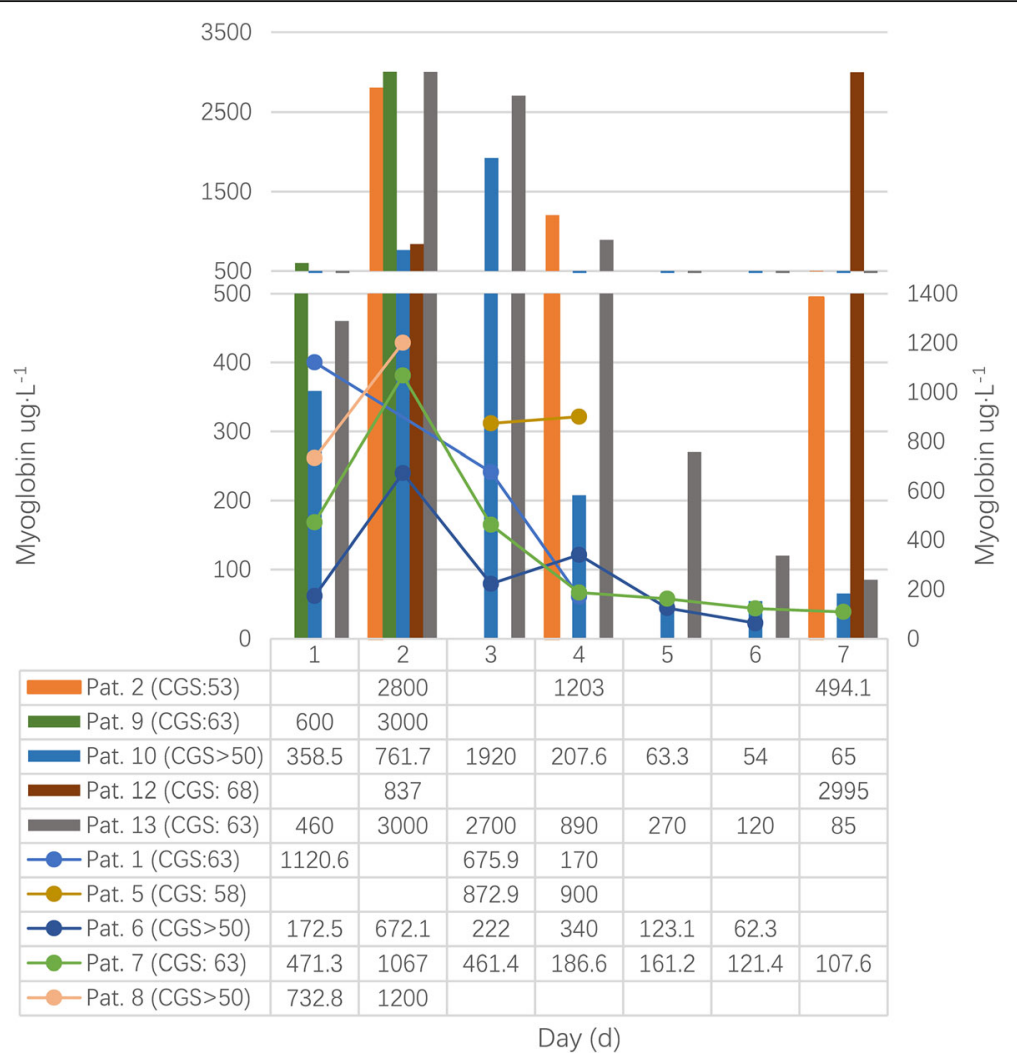

Fig. 5 Changes of myoglobin

of CPK, myoglobin, and CPK-MB between these `almost certain ' cases. Therefore, the low size of these enzyme value might be that they can't be used to rule out $\mathrm{MH}$ episode or determine the severity of $\mathrm{MH}$, which confirm the study made by Carpenter et al. [122] that different RYR1 variants vary in the severity of CPK concentration. Besides, most of the cases' pick time was on the second day, while occasional cases were on the third, fifth, or sixth day.

Almost half of these $\mathrm{MH}$ cases had congenital diseases. Around one in eight of the cases had abnormal enzyme results and mildly elevated body temperature. Therefore, anesthesiologists should take precautions when there are congenital diseases, these abnormal enzyme results or abnormally elevated body temperature for unexplained reason in pre-anesthesia patients and need to avoid administering volatile anesthetics and depolarizing neuromuscular blocking drugs muscle relaxants and strengthen monitoring in the susceptible individuals.

$\mathrm{MH}$ is inherited as an autosomal dominant disorder. Seven members of the immediate family of one patient all took the genetic testing, and except for the patient's father the other six members all tested positive and have $\mathrm{MH}$ susceptibility. Therefore, once $\mathrm{MH}$ episode happens, all family members later need to be advised to take genetic testing, and if the test is positive they are further advised to make warning cards, bracelets, or necklaces with $\mathrm{MH}$ susceptible on them and carry them at all times to alert anesthesiologist, nurse anesthetists, and relevant staffs in case they need anesthesia in the future.

$\mathrm{MH}$ is a rare but life-threatening disorder. When body temperature is over $41^{\circ} \mathrm{C}$, disseminated intravascular coagulation (DIC) is the most common cause of death [1]. The possibility of any complication almost triples per two degrees Celsius rise in maximum body temperature [123]. The lack of dantrolene is the main limitation of $\mathrm{MH}$ treatment. Therefore, early warning and diagnosis and prompt effective therapies are crucial for $\mathrm{MH}$ patients to survive, especially in the countries that dantrolene is not readily available. There is a pressing need to establish an $\mathrm{MH}$ website and a telephone hotline available around the clock in China and countries that have not had these yet, and anesthesiologists, nurse anesthetists, and relevant staff are also urged to register $\mathrm{MH}$ episodes by real-name or anonymity. All information can be collected through the internet and directly uploaded to the national database in real-time. With the consent 


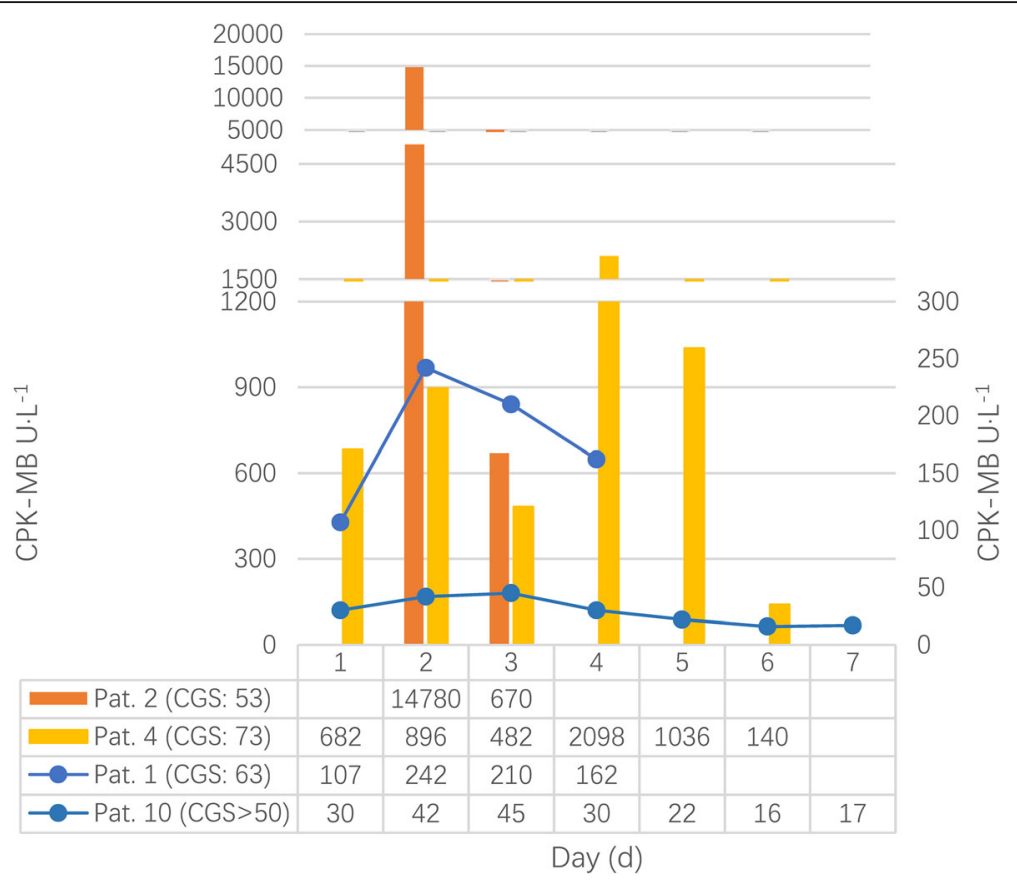

Fig. 6 Changes of CPK-MB. CPK-MB, creatine phosphokinase myocardial band

of those $\mathrm{MH}$ susceptible people, the identity information is uploaded. And the information can only be disclosed in internal systems among hospitals and related units. Once these people need to undergo anesthesia, anesthesiologists, nurse anesthetists, and relevant staff can receive alerts immediately. Besides, the need to carry out extensive publicity and education concerning $\mathrm{MH}$ incidence, clinical presentation, pathophysiology, diagnosis, and treatment is also urgent, not only on professionals and also ordinary people. Let as many people as possible realize the importance and seriousness. $\mathrm{MH}$ susceptible persons would volunteer to upload their identity information by themselves.

In conclusion, in countries that dantrolene is not readily available, early warning, diagnosis, and prompt effective therapies are crucial for $\mathrm{MH}$ patients to survive.

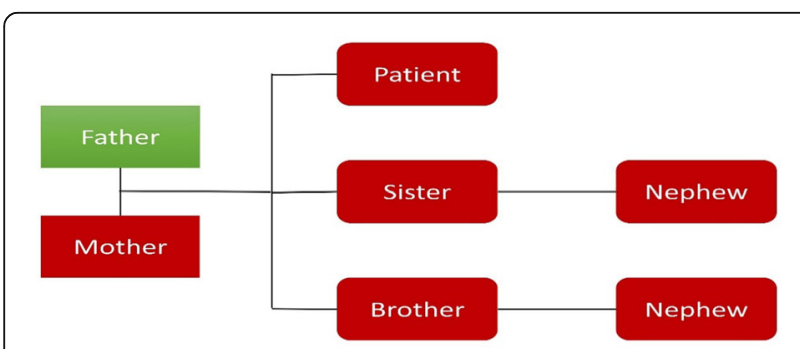

Fig. 7 RYR1 testing result in one family

\section{Abbreviations}

IQR: Interquartile range; MH: Malignant hyperthermia; CGS: Clinical grading scale; CK: Creatine kinase; SD: Standard deviation; $\mathrm{CO}_{2}$ : Carbon dioxide;

ECG: Electrocardiograph; $\mathrm{PCO}_{2}$ : Partial pressure of carbon dioxide; T: Temperature; HR: Heart rate; BP: Blood pressure; CPK: Creatine phosphokinase; CPK-MB: Creatine phosphokinase myocardial band; ALP: Alkaline phosphatase; LDH: Lactic dehydrogenase; DIC: Disseminated intravascular coagulation

\section{Supplementary Information}

The online version contains supplementary material available at https://doi. org/10.1186/s12871-021-01328-3.

Additional file 1: Supplemental Figure S1. Flow chart of the study selection procedure. $\mathrm{MH}$, malignant hyperthermia.

Additional file 2: Supplemental Table S1. The use of vasoactive agents of Malignant hyperthermia cases.

Acknowledgements

Not applicable.

Informed consent

Systematic review: not applicable.

\section{Author's contributions}

$X D$, first author and correspondence author: Study Design, data collection, data analysis, references review, drafting article, critical revision of the article and final approval of the version to be published.

\section{Funding}

Not applicable. Open Access funding enabled and organized by Projekt DEAL.

\section{Availability of data and materials}

The datasets used and analysed during the current study are available from the author on request. 


\section{Declarations}

Ethics approval and consent to participate

Systematic review: not applicable.

\section{Consent for publication}

Systematic review: not applicable.

\section{Competing interests}

The author declares that she has no competing interests.

Received: 17 February 2021 Accepted: 30 March 2021

Published online: 16 April 2021

\section{References}

1. Rosenberg H, Pollock N, Schiemann A, Bulger T, Stowell K. Malignant hyperthermia: a review. Orphanet J Rare Dis. 2015;10(1):93. https://doi.org/1 0.1186/s13023-015-0310-1.

2. Ording H. Incidence of malignant hyperthermia in Denmark. Anesth Analg 1985;64(7):700-4.

3. Lu Z, Rosenberg H, Li G. Prevalence of malignant hyperthermia diagnosis in hospital discharge records in California, Florida, New York, and Wisconsin. J Clin Anesth. 2017;39:10-4. https://doi.org/10.1016/j.jclinane.2017.03.016.

4. Halliday NJ. Malignant hyperthermia. J Craniofac Surg. 2003;14(5):800-2. https://doi.org/10.1097/00001665-200309000-00039.

5. Schneiderbanger D, Johannsen S, Roewer N, Schuster F. Management of malignant hyperthermia: diagnosis and treatment. Ther Clin Risk Manag. 2014;10:355-62. https://doi.org/10.2147/TCRM.S47632.

6. Riazi S, Kraeva N, Hopkins PM. Malignant hyperthermia in the postgenomics era: new perspectives on an old concept. Anesthesiology. 2018; 128(1):168-80. https://doi.org/10.1097/ALN.0000000000001878.

7. Monnier N, Krivosic-Horber R, Payen JF, Kozak-Ribbens G, Nivoche Y, Adnet $P$, et al. Presence of two different genetic traits in malignant hyperthermia families: implication for genetic analysis, diagnosis, and incidence of malignant hyperthermia susceptibility. Anesthesiology. 2002;97(5):1067-74. https://doi.org/10.1097/00000542-200211000-00007.

8. Gonsalves SG, Ng D, Johnston JJ, Teer JK, Stenson PD, Cooper DN, et al. Using exome data to identify malignant hyperthermia susceptibility mutations. Anesthesiology. 2013;119(5):1043-53. https://doi.org/10.1097/A LN.0b013e3182a8a8e7.

9. Denborough M. Malignant hyperthermia. Lancet. 1998;352(9134):1131-6. https://doi.org/10.1016/S0140-6736(98)03078-5.

10. Britt BA, Kalow W. Malignant hyperthermia: a statistical review. Can Anesth Soc J. 1970;17(4):293-315. https://doi.org/10.1007/BF03004694.

11. Larach MG, Localio AR, Allen GC, Denborough MA, Ellis FR, Gronert GA, et al. A clinical grading scale to predict malignant hyperthermia susceptibility. Anesthesiology. 1994;80(4):771-9. https://doi.org/10.1097/00000542-199404 000-00008.

12. An X, Wang Q, Qiu Y, Zhu Z, Ma Z, Li X. Rescue and nursing care of adolescent patients with scoliosis complicated by malignant hyperthermia during posterior orthopedic operations. J Clinic Nursing's Practicality. 2018; 3(5):121-2.

13. Bai J, Chen $X$. The nursing experience of successfully treating a case of malignant hyperthermia during general anesthesia. Nursing Pract Res. 2011; 8(8):122-4.

14. Cai $Y$, Chen $L$, Chen $Y$. A case of malignant hyperthermia after general anesthesia. Chin J Anesthesiology. 2007;27(6):575-6.

15. Cao G, Li J, Yan F. Nursing of patients with malignant hyperthermia after cleft palate repair. J Practical Medical Techniques. 2003;10(8):929.

16. Chen B. A case of death of malignant hyperthermia after cleft lip operation in children. Chin J Anesthesiology. 1995;15(4):192.

17. Chen B. A death case of sudden malignant hyperthermia during general anesthesia. Anthology Med. 1999;18(5):856-7.

18. Chen B, Wang P, Xu J, Tang T. A case report: malignant hyperthermia in general anesthesia. Forum of Anesthesia and Monitoring. 2010;17(6):462

19. Chen H. A case report of malignant hyperthermia. Chinese Community Doctors. 2005;21(271):49.

20. Chen $\mathrm{H}$, Ling $\mathrm{H}$, Yu S. A case of malignant hyperthermia during ophthalmic operation in children. Guangdong Medical Journal. 2003;24(5):456.

21. Chen L. A case of malignant hyperthermia induced by general anesthetics. Tianjin Med J. 1998;26(4):254.
22. Chen Q, Gong L, Yang Q. Rescue of a patient with malignant hyperthermia in general anesthesia. J Nursing (China). 2008;15(8):35-6.

23. Chen $X$, Hao J. Successful treatment of malignant hyperthermia during scoliosis correction: a case report. Chin J Anesthesiology. 2012;32(3):384.

24. Chen Y, Wu J, Chen L, Yang X, Bai H. Malignant hyperthermia after general anesthesia in a child with cerebral palsy. Chin J Contemporary Pediatr. 2011; 13(1):69-70.

25. Chen $Y$, Zhao $T$, Wu H, Chen $G$, Huang H, Xiong L. Successful treatment of malignant hyperthermia: a case report. J Clin Anesth. 2014;30(9):935-6.

26. Dai L. Analysis of one case of malignant hyperthermia induced by sevoflurane. Journal of Clinical Medical Literature. 2014;1(12):2285.

27. Deng $M$, Jiang $X$, Chen W, Zheng D, He X, Yuan H. Successful rescue of one case of suspected familial hereditary malignant hyperthermia. J Clin Anesth. 2020;36(2):204-5.

28. Dong Z. Nursing of malignant hyperthermia in an operation room. J Hebei Med. 2001;7(10):945

29. Feng B. Treatment and nursing care of a patient with malignant hyperthermia complicated with hepatic and renal failure. Modern Nursing 2005;11(16):1372-3.

30. Feng J, Li L, Huang Y, Zhou Z. A death case of malignant hyperthermia during anesthesia. Journal of Tianjin Medical University. 2001;7(2):292-3.

31. Gao J, Niu J, Wu S. A case of malignant hyperthermia in anesthesia. China J Emergency Resuscitation Disaster Medicine. 2007;2(12):748-9.

32. Hou X, Ding H, Feng Q. Experience of successful treatment and nursing of a patient with malignant hyperthermia in general anesthesia. J Nursing (China). 2010;17(6A):58-9.

33. Hu J, Zhang J, Zheng T, Gao Y. Success treatment of malignant hyperthermia in strabismus correction: a case report. Chin J Anesthesiology. 2010;30(9):1152.

34. Hu J, Chen M, Zhou D, Xiao X, Xiong X, Liu Y. Malignant hyperthermia caused by intravenous anesthesia: a case report and literature review. Chin J Integrated Traditional Western Nephrology. 2012;13(5):448-9.

35. Huang D, Zhong L, Yang D, Yu J. Rescuing experience of a patient with malignant hyperthermia. J Clin Anesth. 2002;18(4):215.

36. Huang M, Zeng X. A case of malignant hyperthermia after general anesthesia of cleft lip. J Dental Prevention and Treatment. 1998;6(4):29.

37. Huang S, Wang M. Emergency treatment and nursing of a patient with malignant hyperthermia during general anesthesia. J Nursing (China). 2003; 4:97.

38. Huang W, Zhang M, Wan Z. A case of malignant hyperthermia induced by enflurane. Chin J Anesthesiology. 2001;17(2):114.

39. Huang Y, Chen J, Shen W, Li M. A case of intraoperative malignant hyperthermia. J Clin Anesth. 2004;20(6):329.

40. Ji W, Lin Z. Clinical treatment of malignant hyperthermia. Chin J Emergency Med. 2012;21(8):915-7.

41. Ke J, Yuan J, Jin F, Zhu Z, Zhou X, Xu Q, et al. Treatment of a patient with malignant hyperthermia induced by general anesthesia in facial plastic surgery. Chin J Aesthetic Medicine. 2011;20(4):671-2.

42. Kong Q, Zhou Q. Postoperative malignant hyperthermia in children: two cases report. Hainan Med J. 2001;12(9):70-1.

43. Lan $M$, Jin X. Emergency nursing of a patient with malignant hyperthermia complicated by multiple organs failure. Chin J Practical Nursing. 2007;23: 137.

44. Li F, Tang Q, Yang H, Tang Y. Experience of clinical pharmacists participating in the rescue of malignant hyperthermia. Central South Pharmacy. 2009;7(9): 713-4.

45. Li K, Li T, Wang Y. Successful rescue of a patient with malignant hyperthermia and analysis of family gene test results. Perioperative Safety Quality Assurance. 2018;2(4):212-5.

46. Li Q, Li X, Zhou M, Yang L, Lu Z, Zhu M, et al. Comparison of success and failure factors in the rescue of two patients with malignant hyperthermia. J Clin Anesth. 2004:20(11):692-3.

47. Li S, Weng X, Qiu G. Malignant hyperthermia during scoliosis correction: a case report. Chin J Orthopedics. 2000;20(8):510-1.

48. Li W, Yin J, Wang Y, Xu J. Malignant hyperthermia during general anesthesia in a patient with rare gene mutation. Chin J Anesthesiology. 2016;36(10): 1272-3

49. Li Z, Wu T. A case of malignant hyperthermia in anesthesia. Med J National Defending Forces in Southwest China. 2016;26(4):465-6.

50. Lin $Y$, Liao $Y$, Cai C. Malignant hyperthermia during anesthesia: a case report. J Sichuan University (Medical Science Edition). 2016;47(02):231. 
51. Liu D, Zhao L, Gu S, Qian Y, Wang Y, Xia R, et al. A case of malignant hyperthermia caused by succinylcholine. Chin J Anesthesiology. 2001;21(2): 105.

52. Liu M, Lv L, Peng Y. Three cases of postoperative malignant hyperthermia in children. Chin J Practical pediatrics. 1999;14(10):628-9.

53. Liu Z, Fang L, Teng Y, Zhang F, Cui W, Yan M, et al. Clinical diagnosis and management of malignant hyperthermia. Chin J Emerg Med. 2007;16(10): 1091-2.

54. Lu X. Nursing of one patient with malignant hyperthermia during operation. Modern Nursing. 2005;11(21):1865-6.

55. Lu Y, Ding R, Zhang L. Rescue and nursing of a patient with sudden malignant hyperthermia during operation. J Modern Nursing. 2011;17(19): 2335-6.

56. Lu Z, Chen Y, Tang L, Ling H, Gao C, Gu M, et al. Four cases of malignant hyperthermia during general anesthesia. Chin J Anesthesiology. 2003;23(12): 935-6.

57. Ma Y, Bai L, Wang R, Pan N. A case of malignant hyperthermia during general anesthesia. Med J Chinese People's Liberation Army. 2009;34(11): 1385.

58. Mao Y. Clinical nursing of a case of malignant hyperthermia induced by anesthesia in three-dimensional spinal orthopedics. J Front Med. 2014;9(2): 295-6.

59. Ouyang M, Qin Z, Chen Z, Xiao J, Liu X, Gu M. Successful treatment of explosive malignant hyperthermia in operation: a case report. J Southern Med University. 2010;30(11):2611-2.

60. Pan A. Analysis of a case of malignant hyperthermia during general anesthesia. J Medical Theory Pract. 2011;24(19):2329-30.

61. Shao X. A case of anesthesia complicated with malignant hyperthermia. Jiangsu Medical J. 2007;33(2):126.

62. Shi P. Nursing care of a patient with malignant hyperthermia. Chin J Nurs. 1992;7:316-7.

63. Shi Y. Nursing of a child with acute malignant hyperthermia spastic cerebral palsy during operation. Diet Health Care. 2018;5(52):144.

64. Song YS, Yang J. Malignant hyperthermia. J Clin Anesth. 1985;1(2):5-7.

65. Su Q, Jin F. Clinical nursing of a case of malignant hyperthermia induced by general anesthesia in facial plastic surgery. J Qilu Nursing. 2011;17(20):104-5.

66. Sun Y. Rescue and nursing of a patient with rare congenital multiarticular contracture and scoliosis complicated with malignant hyperthermia during operation. Chin General Practice Nursing. 2016;14(33):3561-2.

67. Tang $Y$, Wang R. Nursing care of a patient with malignant hyperthermia successfully rescued during an operation. Chin J Practical Nursing. 2004; 20(3):47.

68. Tang Z, Wang Y, Guo X. Gu X: diagnosis and treatment of malignant hyperthermia after general anesthesia for cleft lip. West China Journal of Stomatology. 1996;14(1):41-4

69. Tao T, Tian K, Zhang C, Ding H, Hou X, Zhang J, et al. Successful treatment of one case of malignant hyperthermia during cervical discectomy and fusion. Chin J Anesthesiology. 2018;38(12):1535-6.

70. Tian G, Xu K, Gu J, Tao G. Successful treatment of malignant hyperthermia: a case report. J Third Military Med University. 2014;36(12):1290,1298.

71. Wan J. The nursing experience of a patient with sudden malignant hyperthermia under general anesthesia. In: The 10th China Operating Room Nursing Academic Exchange and Special Lecture Conference; 2006. p. 2.

72. Wan X, Wu J. A case of intraoperative malignant hyperthermia. J Clin Anesth. 2012;28(11):1144

73. Wang B, Shen J. Two cases from one family complicated with malignant hyperthermia during general anesthesia. Chin J Postgraduates of Med. 2018; 41(8):757-9

74. Wang C, Ye X, Shi X. Early diagnosis of malignant hyperthermia and treatment in the absence of dantrolene. Acad J Second Mil Univ. 2009; 30(04):369-72

75. Wang L, He M, Wang J. Autopsy of malignant hyperthermia case. Chin J Clin Experimental Pathology. 2015;31(10):1196-7.

76. Wang $M$, Zhang $H$, Sun S. A case of intraoperative malignant hyperthermia. J Clin Anesth. 2006;22(6):439.

77. Wang S. A case of malignant hyperthermia during general anesthesia of branchial cleft cyst. J Community Med. 2009;7(9):84-5.

78. Wang T, Qin Z. A death case of malignant hyperthermia caused by a combination of halothane and succinylcholine chloride. Adverse Drug Reactions Journal. 2015;17(2):159-60.
79. Wang W. Malignant hyperthermia in 3 cases of cleft lip during and after general anesthesia. Curr Phys. 1998;3(3):61.

80. Wang $X$, Cheng L, Shi Y, Wang L. A case report of malignant hyperthermia. Chin J Bone Tumor Bone Dis. 2010;9(6):565-6.

81. Wang X, Lu Y, Qiu Y, Wu L. Diagnosis and treatment of malignant hyperthermia in children with congenital scoliosis. Int J Anesthesiology Resuscitation. 2016;37(1):46-8.

82. Wang Y. A death case of malignant hyperthermia during operation. Shanxi Clinical Med J. 1998;7(7):416-7.

83. Wang $Y$, Xiong L, Cai H. A case of malignant hyperthermia in general anesthesia. J Central South University (Medical Sciences). 2006;31(4):613-4.

84. Wang Z, Yu W, Lu Z, Li X. Gene expression characteristics of two patients with suspected malignant hyperthermia. Chin J Anesthesiology. 2003;23(11): $875-6$.

85. Wei J, Zhang J, Liang Z. A death case of suspected malignant hyperthermia during general anesthesia. J Clin Anesth. 2010;26(10):919.

86. Wu L, Ni S. Treatment of 1 case of anesthetic-induced malignant hyperthermia and literature analysis. China Pharmacy. 2012;23(38):3623-5.

87. Wu Q, Deng J. Nursing in ICU of a patient with malignant hyperthermia in scoliosis surgery. Chin General Pract Nursing. 2019;17(4):506-10.

88. Wu Q, Fang $Y$, Ran X, Fang H, Li Y, Mei W. Experience of successful treatment of a patient with malignant hyperthermia. Perioperative Safety Quality Assurance. 2017:1(5):250-3.

89. Wu R, Li H, Liu J, Li M. A case of malignant hyperthermia in general anesthesia. J Logistics University of CAPF. 2014;23(11):960-1.

90. Xiao J, Gu M, Qin Z, Chen Z, Liang S, Ouyang M, et al. Successful rescue of malignant hyperthermia during operation: a case report. J Clin Anesth. 2010;26(6):551.

91. Xiao J, Gu M, Qin Z, Chen Z, Liang S, Ouyang M, et al. Changes of plasma protease in a patient with malignant hyperthermia and successful rescue: a case report. Guangdong Med J. 2010;31(8):1076.

92. Xin $\mathrm{Q}, \mathrm{Xu} \mathrm{M}$. The nursing experience of a child with malignant hyperthermia complicated with rhabdomyolysis syndrome. Laboratory Med Clinic. 2016;13(SupplementII):412-3.

93. Xiong J. Emergency treatment and nursing of a patient with malignant hyperthermia caused by anesthesia combined with multiple organ failure. Nanfang J Nursing. 2004;11(12):61.

94. $\mathrm{Xu} \mathrm{H}$, Jiang $H$, Huang $H$, Zhu $Y$. Emergency treatment of malignant hyperthermia during oral and maxillofacial surgery: two cases report. China J Oral Maxillofacial Surgery. 2007:5(5):386-8.

95. Xu P, Ge M, Gu Q. Successful rescue of intraoperative malignant hyperthermia combined with multiple organs dysfunction: a case report. Forum of Anesthesia and Monitoring. 2004;11(6):443-4.

96. Xue D, Sun L, Zhang K. Nursing cooperation of one case of suspected malignant hyperthermia after anesthesia induction. Chin J Medical Devices. 2013;28(04):132-3.

97. Yang M, Yang J. Rescue and nursing of a child with malignant hyperthermia during spinal orthopedic operation. World Latest Medicine Information. 2016;16(26):197-8.

98. Yang $Y$. The nursing experience of a patient with malignant hyperthermia during orthognathic operation. In: Chinese oral care academia exchange and special lecture conference, vol. 2004; 2004. p. 4.

99. Yao H. Experience of nursing cooperation in the successful rescue of a patient with malignant hyperthermia. In: The 10th China Operating Room Nursing Academic Exchange and Special Lecture Conference; 2006. p. 737-8.

100. Ye $Y$, Peng $P$, Yang $Y$. The nursing experience of the successful rescue of a patient with sudden malignant hyperthermia during general anesthesia. Nursing J Chinese People's Liberation Army. 2004;21(11):90-1.

101. Yu Y. Nursing report of emergency treatment in ICU for a patient with malignant hyperthermia. Modern Hospital. 2009;9(9):77-8.

102. Zeng J, Li L, Wang Z. Treatment of a case of intraoperative malignant hyperthermia. Lingnan Modern Clinics in Surgery. 2015;15(2):181-4.

103. Zeng R, Zhang J, Xue J, Liu J. A case of death caused by malignant hyperthermia in anesthesia. J Henan Med University. 1997;32(4):127.

104. Zhang A, Dong Q. Delayed malignant hyperthermia after general anesthesia: a case report. J North China Coal Medical Univ. 2002;4(1):97.

105. Zhang C, Zhang Y, Wang M, Wang Z, Zhang A. Role of operating room nurses in the rescue of rare malignant hyperthermia during operation. Med Pharmacy Yunnan. 2017;38(6):651-3.

106. Zhang $\mathrm{H}$, Xie $\mathrm{H}$, Yan $\mathrm{X}$. One death case of malignant hyperthermia after general anesthesia. J Forensic Med. 2008;24(4):313-4. 
107. Zhang L, Shen H, Chen S. A case report of malignant hyperthermia caused by anesthesia. Hainan Med J. 2008;19(1):136-7.

108. Zhang S: Nursing care of a patient with malignant hyperthermia. In: Chinese medicine nursing work experience academic exchange conference: 2002; 2002: 203-204.

109. Zhang X. Experience in successfully treating a child with malignant hyperthermia. Med Inf. 2015;28(12):259.

110. Zhang X, Huang Y, Ge Z, Xu Z, Guo X, Luo A. Clinical diagnosis and management of malignant hyperthermia. Chin J Anesthesiology. 2000;20(8): 454-5.

111. Zhang X, Yang B, Wang W, Long X, Mo Z. A neonatal case of malignant hyperthermia after anesthesia. Chin J Pediatr Surg. 2003;24(4):365.

112. Zhang Y, Yu J. Pathological analysis of a death case caused by malignant hyperthermia. Modern Practical Med. 2012;24(8):887-8.

113. Zhang Z, Gao Y, Gan X, Wang L, Wang Y. Strabismus surgery and malignant hyperthermia in children. Chin J Strabismus Pediatric Ophthalmology. 2013; 21(4):10-1.

114. Zhao A, Li Y. The nursing experience of a patient with malignant hyperthermia during operation. Henan J Diagnosis Therapy. 2002;16(6):4545

115. Zheng $M, X u F, X u J$, Zhang $Y$, Jin $L$. A case of malignant hyperthermia successfully treated. Chin J Anesthesiology. 2005;25(4):248.

116. Zheng $Y, L i C$. Successful rescue of malignant hyperthermia during operation: a case report. Zhejiang Clin Med. 2018;20(3):563-4.

117. Zhou L, Zhao L, Wang J, Xu M, Pu X. Rescue and management of a rare patient with malignant hyperthermia during operation. J Nurses Training. 2002;17(12):949-50.

118. Zhou Y. Beware of malignant hyperthermia induced by anesthesia in cleft lip and palate operation. China Health care and Nutrition. 2014;4:1966-7.

119. Zhu G. Rescue and intensive care of a case of malignant hyperthermia during left cryptorchidism exploration. J Clinic Nursing's Practicality. 2017; 2(49):160-1.

120. Zhu Y, Jiang H, Xu H, Liu H, Chen Z, Huang H. Successful resuscitation of malignant hyperthermia: two cases report. Shanghai Medical Journal. 2005; 28(11):986-7.

121. Zuo J. A case report of successful treatment of malignant hyperthermia. Med Inf. 2013;26(11):208-9.

122. Carpenter D, Robinson RL, Quinnell RJ, Ringrose C, Hogg M, Casson F, et al. Genetic variation in RYR1 and malignant hyperthermia phenotypes. $\mathrm{Br} J$ Anesth. 2009;103(4):538-48. https://doi.org/10.1093/bja/aep204.

123. Larach MG, Gronert GA, Allen GC, Brandom BW, Lehman EB. Clinical presentation, treatment, and complications of malignant hyperthermia in North America from 1987 to 2006. Anesth Analg. 2010;110(2):498-507. https://doi.org/10.1213/ANE.0b013e3181c6b9b2.

\section{Publisher's Note}

Springer Nature remains neutral with regard to jurisdictional claims in published maps and institutional affiliations.

Ready to submit your research? Choose BMC and benefit from:

- fast, convenient online submission

- thorough peer review by experienced researchers in your field

- rapid publication on acceptance

- support for research data, including large and complex data types

- gold Open Access which fosters wider collaboration and increased citations

- maximum visibility for your research: over $100 \mathrm{M}$ website views per year

At BMC, research is always in progress.

Learn more biomedcentral.com/submissions 